\title{
Hypertension in Chronic Kidney Disease: Navigating the Evidence
}

\author{
F. M. Tedla, ${ }^{1}$ A. Brar, ${ }^{1}$ R. Browne, ${ }^{1}$ and C. Brown ${ }^{1,2}$ \\ ${ }^{1}$ Division of Renal Diseases, Department of Medicine, SUNY Downstate Medical Center, 450 Clarkson Avenue, Box 52, \\ Brooklyn, NY 11203, USA \\ ${ }^{2}$ Department of Medicine, Brooklyn Health Disparities Center, SUNY Downstate Medical Center, Brooklyn, NY 11203, USA
}

Correspondence should be addressed to F. M. Tedla, ftedla@downstate.edu

Received 14 February 2011; Accepted 29 March 2011

Academic Editor: Adam T. Whaley-Connell

Copyright ( 2011 F. M. Tedla et al. This is an open access article distributed under the Creative Commons Attribution License, which permits unrestricted use, distribution, and reproduction in any medium, provided the original work is properly cited.

Hypertension is both an important cause and consequence of chronic kidney disease. Evidence from numerous clinical trials has demonstrated the benefit of blood pressure control. However, it remains unclear whether available results could be extrapolated to patients with chronic kidney diseases because most studies on hypertension have excluded patients with kidney failure. In addition, chronic kidney disease encompasses a large group of clinical disorders with heterogeneous natural history and pathogenesis. In this paper, we review current evidence supporting treatment of hypertension in various forms of chronic kidney disease and highlight some of the gaps in the extant literature.

\section{Introduction}

Hypertension is a major risk factor for cardiovascular and renal disease. Conversely, chronic kidney disease (CKD) is the most common form of secondary hypertension and mounting evidence suggests it is an independent risk factor for cardiovascular morbidity and mortality [1-3]. The prevalence of CKD has been better characterized since the National Kidney Foundation issued a standard classification based on the level of glomerular filtration rate (GFR) and the presence or absence of evidence of renal injury. Patients with stages 1 and $2 \mathrm{CKD}$ need to show evidence of renal injury (e.g., proteinuria), and GFR of $\geq 90$ and $60-89 \mathrm{~mL} /$ minute, respectively. Stages 3,4 , and 5 correspond to GFR of 30-59, $15-29$, and $<15 \mathrm{~mL} /$ minute, respectively, regardless of any other evidence of renal damage [4]. It is estimated that 10$13 \%$ of adults in the USA suffer from some degree of CKD $[5]$.

Evidence from a large number of clinical trials has clearly demonstrated that effective treatment ameliorates the harmful effects of uncontrolled hypertension [6]. Unfortunately, most trials have excluded patients with CKD, and those trials that specifically targeted CKD patients primarily focused on progression of renal disease as the primary clinical endpoint. In this paper, we review the epidemiology, pathophysiology, and therapy of hypertension in CKD and highlight the gaps in the available evidence.

\section{Epidemiology}

Approximately one in three adults in the United States has hypertension [7]. The prevalence of hypertension is higher among patients with CKD, progressively increasing with the severity of CKD. Based on a national survey of representative sample of noninstitutionalized adults in the USA, it is estimated that hypertension occurs in $23.3 \%$ of individuals without CKD, and $35.8 \%$ of stage $1,48.1 \%$ of stage $2,59.9 \%$ of stage 3 , and $84.1 \%$ of stage $4-5$ CKD patients [8]. Prevalence of hypertension also varies with the cause of CKD; strong association with hypertension was reported in patients with renal artery stenosis (93\%), diabetic nephropathy $(87 \%)$, and polycystic kidney disease $(74 \%)$ [9].

Despite the high prevalence of hypertension and availability of effective medications, only a minority of patients achieve recommended treatment goals. However, this situation may be changing in the general population. Comparison of recent cohorts with patients in earlier decades shows that awareness and control of hypertension have improved from 
$69 \%$ to $80 \%$ and $27 \%$ to $50 \%$, respectively [7]. Reports on CKD patients enrolled in prospective observational studies have described rates of awareness and control of hypertension as similar to current levels in the general population $[10,11]$. Population data, however, indicate that not only awareness and control of hypertension but also the odds of adequate treatment of other cardiovascular risk factors are lower in those with CKD $[12,13]$. Possible explanations to this discrepancy are the unintended consequence of study participation on clinical care or adherence, and differences in composition of different study populations. Although a sizeable proportion of CKD patients requires multiple antihypertensive agents-32\% were taking four or more anti-hypertensive drugs in one study [10] — nonadherence does not appear to be more common than in patients without CKD [11]. The picture is complicated further by the high prevalence of masked and white-coat hypertension among CKD patients, which results in misclassification of true blood pressure; 24-hour ambulatory blood pressure monitoring may, therefore, be necessary to reliably diagnose hypertension and assess attainment of blood pressure goals [14].

Hypertension is also extremely common among patients on hemodialysis or peritoneal dialysis, and those who have undergone renal transplant. Unlike in patients on peritoneal dialysis, removal fluid in patients on intermittent-thrice weekly hemodialysis is episodic, leading to large differences between pre-, post-, and interdialysis blood pressure. This variation in blood pressure impedes a clear definition of hypertension and target blood pressure in hemodialysis patients. Agarwal and Lewis proposed a cutoff predialysis blood pressure of 150/85 to define hypertension and control; they showed predialysis blood pressure $>150 / 85$ to have $80 \%$ sensitivity in predicting elevated interdialytic ambulatory blood pressure [15]. Based on this definition, they found $86 \%$ of hemodialysis patients had hypertension, of which only $30 \%$ had adequate control [16]. Similar prevalence of hypertension was reported in peritoneal dialysis patients and over $70 \%$ of renal transplant recipients have hypertension $[17,18]$.

Intense controversy surrounds the benefit of blood pressure control in dialysis patients [19]. Analyses of registry data show a U-shaped relationship between blood pressure and mortality. By contrast, studies of selected patients at low risk for cardiovascular disease replicate the observation in the general population that the risk of adverse cardiovascular outcome increases with blood pressure. While the exact pathophysiologic basis for this discrepancy is unclear, it has been suggested that high mortality in dialysis patients with lower blood pressure is due to coexisting severe cardiac disease. In support of this explanation is the favorable outcome seen in the intervention arm of the Frequent Hemodialysis Network (FHN) Daily Trial despite having lower pressure than the control group [20]. In renal transplant recipients, observational studies suggest that posttransplant hypertension is an independent risk factor for graft failure and death, and that adequate blood pressure control reduces this risk [21, 22].

\section{Pathophysiologic Considerations}

The kidneys play such a vital role in long-term blood pressure regulation that Guyton argued that sustained hypertension could not occur in the absence of impairment of renal handling of sodium [23]. In fact, virtually all forms of experimental and human hypertension exhibit impaired sodium excretion by the kidneys at normal blood pressure [24]. In his seminal experiments using large animals and isolated perfused kidneys, Guyton showed that acute rise in blood pressure results in brisk increase in renal sodium excretion and normalization of blood pressure. Conversely, sodium loading increased blood pressure only when renal sodium excretion was constrained by ablation of $70 \%$ of renal mass or administration of angiotensin or aldosterone. Under these circumstances, rise in blood pressure was initially mediated by expansion of extracellular fluid (ECF) volume, despite reduction in total peripheral resistance. At this stage, the rise in blood pressure is mediated by increased cardiac output; this manifests as predominantly systolic hypertension. Over time, however, ECF volume and cardiac output normalize and high blood pressure results from elevated peripheral resistance, which increases diastolic blood pressure.

That subtle renal defects may underlie the pathogenesis of essential hypertension in humans is supported further by several lines of evidence. In a series of patients with renal failure due to histologically proven hypertensive nephrosclerosis, transplant with kidneys from normotensive donors resulted in the resolution of their hypertension [25]. It has also been shown that normotensive individuals with family history of hypertension respond to salt loading with less natriuresis and higher blood pressure than those with no family history [26]. Finally, hypertensive victims of fatal accidents were endowed with fewer nephrons than normotensive controls in an autopsy series [27]. The exact nature of renal defect or defects responsible for inappropriate sodium excretion, or of factors that mediate the subsequent rise in peripheral resistance, remains unclear.

The critical role of volume expansion in hypertension due to CKD is underscored by the effect of ultrafiltration or diuretics on blood pressure control in CKD patients. Dialysis units that employ eight-hour thrice-weekly or short daily hemodialysis report that only a minority of patients require antihypertensive medications for blood pressure control [28]. This observation is confirmed in the FHN Daily Trial, which also showed improvement in the composite outcome of death or left ventricular hypertrophy in the more frequent dialysis group [20]. Similarly, better volume and blood pressure control could be achieved by peritoneal dialysis [29], or use of loop diuretics in earlier stages of CKD [30].

Positive salt balance is the dominant but not the sole factor in the genesis of hypertension in CKD. As noted above, experimental evidence has clearly demonstrated that hypertension due to retention of salt and water is maintained by increased peripheral resistance. This has been replicated in hypertensive uremic humans [31]. Table 1 shows a list of factors proposed to cause hypertension in CKD along with their corresponding mechanisms. 
TABLE 1: Selected factors that may cause hypertension in chronic kidney disease* .

\begin{tabular}{ll}
\hline Factor & Dominant Mechanism \\
\hline Impaired sodium excretion & $\begin{array}{l}\text { Expansion of ECF volume } \\
\text { Direct vasoconstriction } \\
\text { Sympathetic activation }\end{array}$ \\
Activation of RAS & $\begin{array}{l}\text { Direct vasoconstriction } \\
\text { Stimulation of renin release }\end{array}$ \\
Sympathetic activation & Vasoconstriction \\
kinins & $\begin{array}{l}\text { Direct vasoconstriction } \\
\text { Renal injury }\end{array}$ \\
Endothelin & Loss of vasodilator effect \\
\hline Reduced nitric oxide & Ree text for detail. ECF: extracellular fluid; RAS: renin-angiotensin system.
\end{tabular}

Activation of the renin-angiotensin system (RAS) has been well documented in dialysis patients with uncontrolled hypertension despite optimized ultrafiltration [32]. Treatment of such patients with bilateral nephrectomy or inhibitors of RAS has been shown to result in control of blood pressure, suggesting failing kidneys as the source of excess renin $[32,33]$. In addition to its direct pressor effect, it is possible that the activation of the RAS may contribute to hypertension in CKD by stimulating the sympathetic nervous system. In microneurographic studies, patients with CKD have increased sympathetic nerve activity that responds to angiotensin-converting enzyme (ACE) inhibition or bilateral nephrectomy [34]. Even when renal function is well preserved, activation of the RAS is an important factor in the pathogenesis of hypertension in polycystic kidney disease, and is believed to be due to compression of the renal vasculature by enlarging cysts [35]. Other factors proposed to explain increased vascular resistance in CKD include increased production of endothelin [36] and endogenous digitalis-like substance [37]; reduced generation of vasodilators such as nitric oxide [38] and kinins [39]; and imbalance between vasodilator and vasoconstrictor prostaglandins [40]. While the primacy of oxidative stress in hypertension and chronic kidney disease is unknown, it commonly accompanies both disorders and is believed to contribute in part to their pathogenesis [41].

Graft function is an important predictor of hypertension after renal transplant [18]. In addition, calcineurin inhibitors (tacrolimus and cyclosporine) and glucocorticoids contribute to the pathogenesis of hypertension in kidney transplant recipients. Calcineurin inhibitors possess vasoconstrictor properties, but the exact mechanism is not known. Disturbances in the biology of vasoactive substances discussed above and the effect on smooth muscle calcium metabolism have been described [18, 42]. Stenosis of the renal artery of a transplant, or of arteries proximal to the arterial anastomosis, is an infrequent but potentially reversible cause of hypertension after renal transplant.

\section{Treatment of Hypertension in Chronic Kidney Disease}

Patients with CKD are more likely to die, largely from cardiovascular disease, than require dialysis $[43,44]$. Once they develop end-stage renal disease (ESRD), dialysis patients have eight times the mortality rate of their age-matched counterparts in the general population, with cardiovascular causes accounting for more than 50\% of deaths [45]. It is, therefore, critically important to control modifiable risk factors (e.g., hypertension) in this high-risk group.

\section{Blood Pressure Goals}

The latest national guidelines from the Joint National Commission on Prevention, Detection, Evaluation, and Treatment of High Blood Pressure VII (JNC VII) and the Kidney Disease Quality Outcome Initiative (K/DOQI) recommend blood pressure $<130 / 80$ as the goal of treatment for patients with CKD $[46,47]$. As discussed below, there is consistent evidence that attainment of this blood pressure goal retards progression of renal disease in patients with CKD and proteinuria. It is, however, questionable whether this blood pressure goal is applicable to all patients with CKD. First, in patients without significant proteinuria, there are no data supporting more aggressive blood pressure control than what is recommended for hypertensive patients without CKD $(<140 / 90)$. Second, the safety of intensive blood pressure lowering in patients older than 70 years, who have been largely excluded from most clinical trials examining the benefit of blood pressure control, is not established. Third, secondary analyses of prospective studies indicate that patients with CKD may incur excess risk of stroke when systolic blood pressure is lowered below $120 \mathrm{~mm} \mathrm{Hg}$, or of myocardial infarction when diastolic blood pressure is lowered below $80 \mathrm{~mm} \mathrm{Hg}$. [48, 49]. The benefit of treating isolated systolic hypertension in patients with CKD has not been directly tested in a clinical trial. The Systolic Hypertension in the Elderly Program, which excluded patients with renal dysfunction, has shown that treatment of systolic hypertension reduces morbidity and mortality; it is however, important to note that the mean systolic blood pressure attained in the active treatment arm was $143 \mathrm{~mm} \mathrm{Hg}$ [50]. Since patients with CKD tend to be older and have more cardiovascular risk factors, it is advisable to individualize treatment in some patients, especially those who do not have significant proteinuria.

Most clinical trials that examined control of blood pressure in patients with CKD used progression of renal disease as their primary endpoint, and stratified their study population by the degree of proteinuria or etiology of kidney disease. In the following sections, the evidence for benefits of blood pressure treatment will be discussed separately for diabetic nephropathy, other proteinuric renal diseases, and nonproteinuric nephropathy. Table 2 summarizes treatment of hypertension in CKD according to the nature of kidney disease. 
TABLE 2: Summary of treatment of hypertension in chronic kidney disease*.

\begin{tabular}{lll}
\hline Disorder & BP Goal & Preferred Class \\
\hline $\begin{array}{l}\text { Diabetic nephropathy } \\
\begin{array}{l}\text { Nondiabetic proteinuric } \\
\text { nephropathy }\end{array}\end{array}$ & $<130 / 80$ & ACEI/ARB \\
$\begin{array}{l}\text { Nonproteinuric } \\
\text { nephropathy }\end{array}$ & $<140 / 90$ & ACEI/ARB \\
Renal transplant & Anknown & $\begin{array}{l}\text { Any; caution } \\
\text { with verapamil } \\
\text { or diltiazem }\end{array}$ \\
\hline
\end{tabular}

${ }^{*}$ See text for details. BP: blood pressure; ACEI: angiotensin-converting enzyme inhibitor; ARB: angiotensin-receptor blocker.

\section{Treatment of Hypertension in Diabetic Nephropathy}

It is generally accepted that treatment of diabetic nephropathy should include an ACE inhibitor or angiotensin-receptor blocker (ARB) to attain a blood pressure goal of less than 130/80 mmHg. Most [51-55], but not all [56-58], clinical trials that examined the impact of specific class of antihypertensive agents on worsening of proteinuria or renal function in diabetic nephropathy found that ACE inhibitors or ARBs are renoprotective. In patients with type 1 diabetes, treatment with captopril retarded progression of microalbuminuria (daily urinary excretion of albumin of 30-300 mg) to overt proteinuria $[51,52]$, and of overt nephropathy to ESRD [53]. Two large clinical trials also showed that use of the ARBs irbesartan and losartan in patients with overt diabetic nephropathy due to type 2 diabetes reduced the risk of progression of renal disease $[54,55]$.

The benefit of attaining the currently recommended goal blood pressure of $<130 / 80$ has not been directly tested in clinical trials of diabetic nephropathy. Secondary analyses of existing trials, however, suggest that lowering blood pressure to this level may improve renal and cardiovascular outcomes. The United Kingdom Prospective Diabetes Study (UKPDS) compared the effect of lowering blood pressure below 150/85 and $180 / 85 \mathrm{mmHg}$ in patients with type 2 diabetes and hypertension [59]. Patients with laser-requiring diabetic retinopathy and serum creatinine $>2 \mathrm{mg} / \mathrm{dL}$ were excluded; mean blood pressure attained in the tight- and usual-control groups was $144 / 82$ and $152 / 87 \mathrm{~mm} \mathrm{Hg}$, respectively, and more than $80 \%$ of patients had urinary albumin excretion $<50 \mathrm{mg} / \mathrm{L}$. In a posthoc analysis of the original data, the authors found no blood pressure threshold for the beneficial effect of blood pressure lowering and recommended aiming for systolic blood pressure of $120 \mathrm{~mm} \mathrm{Hg}$ or lower in diabetic patients with hypertension [60].

The Irbesartan in Diabetic Nephropathy Trial (IDNT) assessed the renoprotective effects of adding irbesartan, amlodipine, or placebo to standard antihypertensive regimens [54]. All three groups had a median daily urinary protein excretion of 1.9 grams, and the attained blood pressure in the irbesartan, amlodipine, and placebo groups was 140/77, 141/77, and 144/80 $\mathrm{mm} \mathrm{Hg}$, respectively. Secondary analyses of IDNT showed that progressive lowering of blood pressure up to systolic blood pressure of $120 \mathrm{mmHg}$ protects against cardiovascular events and deterioration of renal function, but further reduction in blood pressure is deleterious; a similar trend up to diastolic blood pressure of $85 \mathrm{mmHg}$ was observed for cardiovascular but not renal endpoints $[49,61]$.

The normotensive Appropriate Blood Pressure Control in Diabetes (ABCD) and Modification of Diet in Renal Disease (MDRD) studies are two other trials that failed to prove the value of lower blood pressure for their primary endpoints, but suggested a beneficial effect in post-hoc analyses $[57,58]$. The normotensive ABCD trial compared intensive with moderate blood pressure lowering using nisoldipine or enalapril in normotensive patients with type 2 diabetes. Attained blood pressure in the intensive and moderate treatment arms was $128 / 75$ and $137 / 81 \mathrm{~mm} \mathrm{Hg}$, respectively; corresponding rates of microalbuminuria were $21 \%$ and $25 \%$. There was no difference in the rate of decline of renal function - the primary endpoint-but lesser degree of proteinuria was noted with intensive therapy. No difference was noted between the nisoldipine and enalapril arms. The MDRD study largely consisted of nondiabetic patients; it compared the effect of intensive versus usual blood pressure control, and low versus high protein intake on renal function. The study showed no difference in the primary outcome between the different arms, but subgroup analysis showed that lowering mean blood pressure to $92 \mathrm{mmHg}$ (equivalent to $125 / 75 \mathrm{~mm} \mathrm{Hg}$ ) preserved renal function in those with proteinuria of $>3 \mathrm{~g} /$ day, or $>1 \mathrm{~g} /$ day in a subset with glomerular filtration rate of $25-55 \mathrm{ml} / \mathrm{min} / 1.73 \mathrm{~m}^{2}$ $[58,62]$.

As the above summary shows, careful review of the data that underpin the recommendation for lowering BP to $<130 / 80$ in patients with diabetic nephropathy calls for caution in applying the guideline universally; most studies did not attain this level of control, and the recommendation is based mainly on post hoc analysis. This is especially true in light of the results of the Action to Control Cardiovascular Risk in Diabetes Blood Pressure (ACCORD BP) trial [63]. This large trial of diabetic patients with cardiovascular disease or at least two additional risk factors for cardiovascular disease evaluated the impact of lowering systolic blood pressure below 120 or $140 \mathrm{~mm} \mathrm{Hg}$. Study participants had mean serum creatinine of $0.9 \mathrm{mg} / \mathrm{dL}$ and minimal or no proteinuria. Despite attaining systolic blood pressure of 119 and $135 \mathrm{~mm} \mathrm{Hg}$ with intensive and standard therapy, there was no difference in the composite primary endpoint (nonfatal stroke, nonfatal myocardial infarction, or cardiovascular death) or all-cause mortality between the two groups. The intensive control group had lower risk of stroke, but at the expense of higher rates of serious side effects.

\section{Treatment in Nondiabetic Proteinuric Nephropathy}

Evidence from controlled clinical trials indicates that blood pressure control limits the progression of nondiabetic 
proteinuric renal disease. The MDRD study, as discussed above, suggested that the degree of proteinuria determines the beneficial effect derived from tight blood pressure control [58]. Although no additional benefit from use of ACE inhibitors was found in the MDRD trial, subsequent randomized controlled studies support the use of ACE inhibitors for renoprotection, especially in those patients with significant proteinuria (daily urinary protein excretion of $1 \mathrm{gm}$ or more) $[64,65]$. Since these studies have not attained blood pressure $<130 / 80$, the best available evidence for targeting blood pressure below this level is obtained from subgroup analysis of the MDRD study. Data on the use of ARBs in nondiabetic proteinuric renal disease are limited, but ARBs are generally believed to be equivalent to ACE inhibitors [66]. Unlike their support for renoprotection, these studies do not provide adequate data on the impact of blood pressure control on cardiovascular outcomes.

\section{Treatment in Nonproteinuric Nephropathy}

The benefit of tighter blood pressure control than $<140 / 90$, or of the use of ACE inhibitors or ARBs, in nonproteinuric nephropathy has not been established. In the African American Study of Kidney Disease and Hypertension (AASK), patients were randomized to treatment with ramipril, amlodipine, or metoprolol and to low and usual blood pressure targets [67]. The amlodipine arm was terminated prematurely because interim analysis implied that it had worse outcome than those treated with ramipril. Approximate two-thirds of the participants had urine protein-tocreatinine ratio less than 0.22 (equivalent to $300 \mathrm{mg} /$ day) at baseline. Attained blood pressure in the low- and usual-blood-pressure groups was 128/78 and 141/85 mm Hg, respectively. There was no difference in the rate of progression of renal disease, but ramipril appeared more effective than amlodipine or metoprolol in decreasing the composite secondary outcome of worsening renal function, ESRD, or death. A long-term followup of the AASK cohort suggested this benefit accrued in those with higher levels of proteinuria [68]. Absence of additional benefit from tighter blood pressure control or use of ACE inhibitors has also been noted in patients with polycystic kidney disease, a condition that is not characterized by heavy proteinuria $[69,70]$.

\section{Combination Therapy}

Most patients with CKD require more than one antihypertensive medication for treatment of hypertension. Choosing agents that have complementary mechanisms of actions or are indicated to address other comorbid conditions is a useful strategy to optimize therapy and minimize side effects. Loop diuretics are often necessary to treat volume overload or hyperkalemia.

Dual blockade with ACE inhibitors and ARBs reduces proteinuria to a greater degree than either class alone, but has not been proven to preserve renal function or improve cardiovascular outcomes [71]. Of concern is the increased risk of adverse events observed in the Ongoing Telmisartan
Alone and in Combination with Ramipril Global Endpoint Trial (ONTARGET) [72]. In this large trial of patients at high risk for vascular disease, the mean serum creatinine was approximately $1.1 \mathrm{mg} / \mathrm{dL}$, one-third of the participants were normotensive, and only $13 \%$ of patients had microalbuminuria; dual blockade was associated with worse renal function and hyperkalemia, and there was no difference in cardiovascular events or mortality. Combining aldosterone antagonists with inhibitors of the RAS, although possessing additional antiproteinuric effects, should be discouraged for the same reasons-lack of proven clinical benefit and increased risk of side effects [73].

The role and safety of combination blockade of the RAS consisting of a direct renin inhibitor in patients with CKD are not yet fully elucidated. The Aliskiren in the Evaluation of Proteinuria in Diabetes (AVOID) trial studied a group of carefully selected diabetic patients with GFR $>30 \mathrm{ml} / \mathrm{min} / 1.73 \mathrm{~m}^{2}$ and no evidence of hyperkalemia; the addition of aliskiren to losartan was well tolerated and reduced albuminuria [74]. Results of future studies, including that of an ongoing clinical trial of diabetic patients with similar degree of CKD as in AVOID [75], may answer whether combination blockade of the RAS using direct renin inhibitors results in improvement of hard clinical endpoints.

\section{Nonpharmacologic Therapy}

Although pharmacologic therapy is often necessary to control blood pressure in most patients with CKD, sodium restriction, smoking cessation, moderate alcohol consumption, weight loss, and regular exercise should be part of a comprehensive strategy of effective treatment of hypertension in CKD. Dietary recommendations need to be modified according to the stage of CKD to optimally regulate protein, phosphorus, and potassium intake [47].

\section{Treatment of Renal Artery Stenosis}

Atherosclerotic renal artery stenosis could cause hypertension and CKD. Since most lesions are asymptomatic, the true prevalence is not known. Studies of insurance claims data and patients undergoing angiography for unrelated indications report wide variations in prevalence ranging from $0.5 \%$ to as high as $45 \%[76,77]$. The natural history of the disease is also controversial, with only a minority of patients developing progressive renal failure or intractable hypertension [78]. To date, controlled clinical trials have not demonstrated the superiority of percutaneous revascularization over medical therapy [79-82]. These studies, however, spanned a long period of time and employed different interventions, entry criteria, treatment protocols, and endpoints. Until the results of a large ongoing trial clarify the role of revascularization [83], medical therapy of hypertension and other atherosclerotic factors remains the mainstay of treatment of atherosclerotic renal artery stenosis. Revascularization may be warranted in patients with recurrent pulmonary edema, solitary or transplanted kidney, or worsening renal failure. 


\section{Treatment of Hypertension after Renal Transplant}

Based on evidence for native chronic kidney disease, K/DOQI recommends aiming for blood pressure $<130 / 80$ in renal transplant recipients. As discussed above, the applicability of this goal to patients who do not have proteinuric native kidney disease has not been established. Whether specific classes of antihypertensive agents provide additional benefit to transplant recipients beyond what is obtained from control of blood pressure per se is also not known. As long as there are no specific contraindications against or compelling indications for a specific class of agents, any antihypertensive agent could be used in transplant recipients. Close monitoring is warranted when using nondihydropyridine calcium channel blockers (diltiazem, verapamil) and inhibitors of the RAS because the former inhibit metabolism of immunosuppressive agents by the cytochrome P450 system, and the latter could result in hyperkalemia $[84,85]$.

\section{Experimental Approaches}

Advances in device technology have allowed the resurgence of invasive prepharmacotherapy interventions for resistant hypertension that were abandoned because of technical difficulties or excessive morbidity. Preliminary results of carotid sinus stimulation and catheter-based renal sympathetic denervation suggest that sustained reduction in blood pressure could be achieved with acceptable risks [86, 87]. If these early results could be replicated in diverse clinical settings, including patients with CKD, they would expand the range of options for the treatment of resistant hypertension.

\section{Summary}

Treatment of hypertension in CKD patients should take into consideration the nature of the underlying kidney disease. Patients with diabetic nephropathy or proteinuric nondiabetic kidney disease benefit from treatment with ACE inhibitors or ARBs to a goal blood pressure of $<130 / 80 \mathrm{~mm} \mathrm{Hg}$, if tolerated. A goal of $<140 / 90 \mathrm{~mm} \mathrm{Hg}$ is acceptable for most patients with other forms of CKD. Dual or triple blockade of the RAS should generally be avoided.

\section{References}

[1] A. M. Sinclair, C. G. Isles, I. Brown, H. Cameron, G. D. Murray, and J. W. Robertson, "Secondary hypertension in a blood pressure clinic," Archives of Internal Medicine, vol. 147, pp. 1289-1293, 1987.

[2] A. S. Go, G. M. Chertow, D. Fan, C. E. McCulloch, and C. Y. Hsu, "Chronic kidney disease and the risks of death, cardiovascular events, and hospitalization," New England Journal of Medicine, vol. 351, no. 13, pp. 1296-1305, 2004.

[3] N. S. Anavekar, J. J. V. McMurray, E. J. Velazquez et al., "Relation between renal dysfunction and cardiovascular outcomes after myocardial infarction," New England Journal of Medicine, vol. 351, no. 13, pp. 1285-1295, 2004.
[4] A. S. Levey, J. Coresh, K. Bolton et al., "K/DOQI clinical practice guidelines for chronic kidney disease: Evaluation, classification, and stratification," American Journal of Kidney Diseases, vol. 39, no. 2, pp. S1-S266, 2002.

[5] J. Coresh, E. Selvin, L. A. Stevens et al., "Prevalence of chronic kidney disease in the United States," Journal of the American Medical Association, vol. 298, no. 17, pp. 2038-2047, 2007.

[6] F. Turnbull, "Effects of different blood-pressure-lowering regimens on major cardiovascular events: Results of prospectivelydesigned overviews of randomised trials," Lancet, vol. 362, no. 9395, pp. 1527-1535, 2003.

[7] B. M. Egan, Y. Zhao, and R. N. Axon, "US trends in prevalence, awareness, treatment, and control of hypertension, 19882008," Journal of the American Medical Association, vol. 303, no. 20, pp. 2043-2050, 2010.

[8] 8. U S Renal Data System, USRDS 2010 Annual Data Report: Atlas of Chronic Kidney Disease and End-Stage Renal Disease in the United States, National Institutes of Health, National Institute of Diabetes and Digestive and Kidney Diseases. Bethesda, Md, USA, 2010.

[9] N. Ridao, J. Luño, S. García De Vinuesa, F. Gómez, A. Tejedor, and F. Valderrábano, "Prevalence of hypertension in renal disease," Nephrology Dialysis Transplantation, vol. 16, no. 1, pp. 70-73, 2001.

[10] P. Muntner, A. Anderson, J. Charleston et al., "Hypertension awareness, treatment, and control in adults with CKD: results from the chronic renal insufficiency cohort (CRIC) study," American Journal of Kidney Diseases, vol. 55, no. 3, pp. 441451, 2010.

[11] P. Muntner, S. E. Judd, M. Krousel-Wood, W. M. McClellan, and M. M. Safford, "Low medication adherence and hypertension control among adults with CKD: data from the REGARDS (Reasons for Geographic and Racial Differences in Stroke) study," American Journal of Kidney Diseases, vol. 56, pp. 447-457, 2010.

[12] J. J. Snyder and A. J. Collins, "KDOQI hypertension, dyslipidemia, and diabetes care guidelines and current care patterns in the united states CKD population: National health and nutrition examination survey 1999-2004," American Journal of Nephrology, vol. 30, no. 1, pp. 44-54, 2009.

[13] P. A. Sarafidis, S. Li, S. C. Chen et al., "Hypertension awareness, treatment, and control in chronic kidney disease," American Journal of Medicine, vol. 121, no. 4, pp. 332-340, 2008.

[14] F. Bangash and R. Agarwal, "Masked hypertension and whitecoat hypertension in chronic kidney disease: A meta-analysis," Clinical Journal of the American Society of Nephrology, vol. 4, no. 3, pp. 656-664, 2009.

[15] R. Agarwal and R. R. Lewis, "Prediction of hypertension in chronic hemodialysis patients," Kidney International, vol. 60, no. 5, pp. 1982-1989, 2001.

[16] R. Agarwal, A. R. Nissenson, D. Batlle, D. W. Coyne, J. R. Trout, and D. G. Warnock, "Prevalence, treatment, and control of hypertension in chronic hemodialysis patients in the United States," American Journal of Medicine, vol. 115, no. 4, pp. 291297, 2003.

[17] R. Cocchi, E. D. Esposti, A. Fabbri et al., "Prevalence of hypertension in patients on peritoneal dialysis: results of an Italian multicentre study," Nephrology Dialysis Transplantation, vol. 14, no. 6, pp. 1536-1540, 1999.

[18] F. Tedla, R. Hayashi, S. I. McFarlane, and M. O. Salifu, "Hypertension after renal transplant," Journal of Clinical Hypertension, vol. 9, no. 7, pp. 538-545, 2007. 
[19] K. L. Lynn, "Hypertension and survival in hemodialysis patients," Seminars in Dialysis, vol. 17, no. 4, pp. 270-274, 2004.

[20] G. M. Chertow, N. W. Levin, G. J. Beck et al., "In-center hemodialysis six times per week versus three times per week," New England Journal of Medicine, vol. 363, no. 24, pp. 22872300, 2010.

[21] B. L. Kasiske, S. Anjum, R. Shah et al., "Hypertension after kidney transplantation," American Journal of Kidney Diseases, vol. 43, no. 6, pp. 1071-1081, 2004.

[22] G. Opelz and B. Döhler, "Improved long-term outcomes after renal transplantation associated with blood pressure control," American Journal of Transplantation, vol. 5, no. 11, pp. 27252731, 2005.

[23] A. C. Guyton, T. G. Coleman, D. B. Young, T. E. Lohmeier, and J. W. DeClue, "Salt balance and long-term blood pressure control," Annual Review of Medicine, vol. 31, pp. 15-27, 1980.

[24] J. E. Hall, “The kidney, hypertension, and obesity," Hypertension, vol. 41, no. 3, pp. 625-633, 2003.

[25] J. J. Curtis, R. G. Luke, and H. P. Dustan, "Remission of essential hypertension after renal transplantation," New England Journal of Medicine, vol. 309, no. 17, pp. 1009-1015, 1983.

[26] B. R. Widgren, H. Herlitz, T. Hedner et al., "Blunted renal sodium excretion during acute saline loading in normotensive men with positive family histories of hypertension," American Journal of Hypertension, vol. 4, no. 7 I, pp. 570-578, 1991.

[27] G. Keller, G. Zimmer, G. Mall, E. Ritz, and K. Amann, "Nephron number in patients with primary hypertension," New England Journal of Medicine, vol. 348, no. 2, pp. 101-108, 2003.

[28] E. Saad, B. Charra, and D. S. C. Raj, "Hypertension control with daily dialysis," Seminars in Dialysis, vol. 17, no. 4, pp. 295-298, 2004.

[29] A. I. Günal, S. Duman, M. Özkahya et al., "Strict volume control normalizes hypertension in peritoneal dialysis patients," American Journal of Kidney Diseases, vol. 37, no. 3, pp. 588593, 2001.

[30] N. Vasavada and R. Agarwal, "Role of excess volume in the pathophysiology of hypertension in chronic kidney disease," Kidney International, vol. 64, no. 5, pp. 1772-1779, 2003.

[31] K. E. Kim, G. Onesti, A. B. Schwartz, J. L. Chinitz, and C. Swartz, "Hemodynamics of hypertension in chronic end-stage renal disease," Circulation, vol. 46, no. 3, pp. 456-464, 1972.

[32] P. Weidmann, M. H. Maxwell, A. N. Lupu, A. J. Lewin, and S. G. Massry, "Plasma renin activity and blood pressure in terminal renal failure," New England Journal of Medicine, vol. 285, no. 14, pp. 757-762, 1971.

[33] E. D. Vaughan Jr., R. M. Carey, C. R. Ayers, and M. J. Peach, "Hemodialysis-resistant hypertension: Control with an orally active inhibitor of angiotensin-converting enzyme," Journal of Clinical Endocrinology and Metabolism, vol. 48, no. 5, pp. 869871, 1979.

[34] R. A. Augustyniak, M. Tuncel, W. Zhang, R. D. Toto, and R. G. Victor, "Sympathetic overactivity as a cause of hypertension in chronic renal failure," Journal of Hypertension, vol. 20, no. 1, pp. 3-9, 2002.

[35] A. B. Chapman, A. Johnson, P. A. Gabow, and R. W. Schrier, "The renin-angiotensin-aldosterone system and autosomal dominant polycystic kidney disease," New England Journal of Medicine, vol. 323, no. 16, pp. 1091-1096, 1990.

[36] D. E. Kohan, "Endothelins in the normal and diseased kidney," American Journal of Kidney Diseases, vol. 29, no. 1, pp. 2-26, 1997.
[37] M. P. Blaustein, J. Zhang, L. Chen et al., "The pump, the exchanger, and endogenous ouabain: signaling mechanisms that link salt retention to hypertension," Hypertension, vol. 53, no. 2, pp. 291-298, 2009.

[38] N. D. Vaziri, "Effect of chronic renal failure on nitric oxide metabolism," American Journal of Kidney Diseases, vol. 38, no. 4, pp. S74-S79, 2001.

[39] J. A. Mitas, S. B. Levy, and R. Holle, "Urinary kallikrein activity in the hypertension of renal parenchymal disease," New England Journal of Medicine, vol. 299, no. 4, pp. 162-165, 1978.

[40] M. J. Dunn and V. L. Hood, "Prostaglandins and the kidney," The American Journal of Physiology, vol. 233, no. 3, pp. 169184, 1977.

[41] N. D. Vaziri, "Roles of oxidative stress and antioxidant therapy in chronic kidney disease and hypertension," Current Opinion in Nephrology and Hypertension, vol. 13, no. 1, pp. 93-99, 2004.

[42] P. G. McNally and J. Feehally, "Pathophysiology of cyclosporin A nephrotoxicity: experimental and clinical observations," Nephrology Dialysis Transplantation, vol. 7, no. 8, pp. 791-804, 1992.

[43] R. N. Foley, A. M. Murray, S. Li et al., "Chronic kidney disease and the risk for cardiovascular disease, renal replacement, and death in the United States medicare population, 1998 to 1999," Journal of the American Society of Nephrology, vol. 16, no. 2, pp. 489-495, 2005.

[44] D. S. Keith, G. A. Nichols, C. M. Gullion, J. B. Brown, and D. H. Smith, "Longitudinal follow-up and outcomes among a population with chronic kidney disease in a large managed care organization," Archives of Internal Medicine, vol. 164, no. 6, pp. 659-663, 2004.

[45] U.S. Renal Data System, USRDS 2008 Annual Data Report: Atlas of Chronic Kidney Disease and End-Stage Renal Disease in the United States, National Institutes of Health, National Institute of Diabetes and Digestive and Kidney Diseases, Bethesda, Md, USA, 2008.

[46] A. V. Chobanian, G. L. Bakris, H. R. Black et al., "The seventh report of the joint national committee on prevention, detection, evaluation, and treatment of high blood pressure: the JNC 7 report," Journal of the American Medical Association, vol. 289, no. 19, pp. 2560-2572, 2003.

[47] A. S. Levey, M. V. Rocco, S. Anderson et al., "K/DOQI clinical practice guidelines on hypertension and antihypertensive agents in chronic kidney disease," American Journal of Kidney Diseases, vol. 43, no. 5, pp. S1-S290, 2004.

[48] D. E. Weiner, H. Tighiouart, A. S. Levey et al., "Lowest systolic blood pressure is associated with stroke in stages 3 to 4 chronic kidney disease," Journal of the American Society of Nephrology, vol. 18, no. 3, pp. 960-966, 2007.

[49] T. Berl, L. G. Hunsicker, J. B. Lewis et al., "Impact of achieved blood pressure on cardiovascular outcomes in the Irbesartan Diabetic Nephropathy Trial," Journal of the American Society of Nephrology, vol. 16, no. 7, pp. 2170-2179, 2005.

[50] J. L. Probstfield, "Prevention of stroke by antihypertensive drug treatment in older persons with isolated systolic hypertension: final results of the Systolic Hypertension in the Elderly Program (SHEP)," Journal of the American Medical Association, vol. 265, no. 24, pp. 3255-3264, 1991.

[51] G. Viberti, C. E. Mogensen, L. C. Groop, and J. F. Pauls, "Effect of captopril on progression to clinical proteinuria in patients with insulin-dependent diabetes mellitus and microalbuminuria," Journal of the American Medical Association, vol. 271, no. 4, pp. 275-279, 1994. 
[52] G. Boner, D. J. Van Dyk, M. H. Tan et al., "Captopril reduces the risk of nephropathy in IDDM patients with microalbuminuria," Diabetologia, vol. 39, no. 5, pp. 587-593, 1996.

[53] E. J. Lewis, L. G. Hunsicker, R. P. Bain, and R. D. Rohde, "The effect of angiotensin-converting-enzyme inhibition on diabetic nephropathy," New England Journal of Medicine, vol. 329, no. 20, pp. 1456-1462, 1993.

[54] E. J. Lewis, L. G. Hunsicker, W. R. Clarke et al., "Renoprotective effect of the angiotensin-receptor antagonist irbesartan in patients with nephropathy due to type 2 diabetes," New England Journal of Medicine, vol. 345, no. 12, pp. 851-860, 2001.

[55] B. M. Brenner, M. E. Cooper, D. De Zeeuw et al., "Effects of losartan on renal and cardiovascular outcomes in patients with type 2 diabetes and nephropathy," New England Journal of Medicine, vol. 345, no. 12, pp. 861-869, 2001.

[56] R. O. Estacio, B. W. Jeffers, N. Gifford, and R. W. Schrier, "Effect of blood pressure control on diabetic microvascular complications in patients with hypertension and type 2 diabetes," Diabetes Care, vol. 23, no. 2, pp. B54-B64, 2000.

[57] R. W. Schrier, R. O. Estacio, A. Esler, and P. Mehler, "Effects of aggressive blood pressure control in normotensive type 2 diabetic patients on albuminuria, retinopathy and strokes," Kidney International, vol. 61, no. 3, pp. 1086-1097, 2002.

[58] S. Klahr, A. S. Levey, G. J. Beck et al., "The effects of dietary protein restriction and blood-pressure control on the progression of chronic renal disease," New England Journal of Medicine, vol. 330, no. 13, pp. 877-884, 1994.

[59] UK Prospective Diabetes Study Group, “Tight blood pressure control and risk of macrovascular and microvascular complications in type 2 diabetes: UKPDS 38," British Medical Journal, vol. 317, pp. 703-713, 1999.

[60] A. I. Adler, I. M. Stratton, H. A. W. Neil et al., "Association of systolic blood pressure with macrovascular and microvascular complications of type 2 diabetes (UKPDS 36): prospective observational study," British Medical Journal, vol. 321, no. 7258, pp. 412-419, 2000.

[61] M. A. Pohl, S. Blumenthal, D. J. Cordonnier et al., "Independent and additive impact of blood pressure control and angiotensin II receptor blockade on renal outcomes in the irbesartan diabetic nephropathy trial: Clinical implications and limitations," Journal of the American Society of Nephrology, vol. 16, no. 10, pp. 3027-3037, 2005.

[62] M. J. Sarnak, T. Greene, X. Wang et al., "The effect of a lower target blood pressure on the progression of kidney disease: Long-term follow-up of the modification of diet in renal disease study," Annals of Internal Medicine, vol. 142, no. 5, pp. 342-351, 2005.

[63] W. C. Cushman, G. W. Evans, R. P. Byington et al., "Effects of intensive blood-pressure control in type 2 diabetes mellitus," New England Journal of Medicine, vol. 362, no. 17, pp. 1575$1585,2010$.

[64] G. Remuzzi, "Randomised placebo-controlled trial of effect of ramipril on decline in glomerular filtration rate and risk of terminal renal failure in proteinuric, non-diabetic nephropathy," Lancet, vol. 349, no. 9069, pp. 1857-1863, 1996.

[65] P. Ruggenenti, A. Perna, G. Loriga et al., "Blood-pressure control for renoprotection in patients with non-diabetic chronic renal disease (REIN-2): multicentre, randomised controlled trial," Lancet, vol. 365, no. 9463, pp. 939-946, 2005.

[66] P. K. T. Li, C. B. Leung, K. M. Chow et al., "Hong Kong study using valsartan in IgA nephropathy (HKVIN): a double-blind, randomized, placebo-controlled study," American Journal of Kidney Diseases, vol. 47, no. 5, pp. 751-760, 2006.

[67] J. T. Wright Jr., G. Bakris, T. Greene et al., "Effect of blood pressure lowering and antihypertensive drug class on progression of hypertensive kidney disease: Results from the AASK trial," Journal of the American Medical Association, vol. 288, no. 19, pp. 2421-2431, 2002.

[68] L. J. Appel, J. T. Wright Jr., T. Greene et al., "Intensive bloodpressure control in hypertensive chronic kidney disease," New England Journal of Medicine, vol. 363, no. 10, pp. 918-929, 2010.

[69] G. Maschio, D. Alberti, G. Janin et al., "Effect of the angiotensin-converting-enzyme inhibitor benazepril on the progression of chronic renal insufficiency," New England Journal of Medicine, vol. 334, no. 15, pp. 939-945, 1996.

[70] R. Schrier, K. McFann, A. Johnson et al., "Cardiac and renal effects of standard versus rigorous blood pressure control in autosomal-dominant polycystic kidney disease: results of a seven-year prospective randomized study," Journal of the American Society of Nephrology, vol. 13, no. 7, pp. 1733-1739, 2002.

[71] R. Kunz, C. Friedrich, M. Wolbers, and J. F. E. Mann, "Metaanalysis: effect of monotherapy and combination therapy with inhibitors of the renin-angiotensin system on proteinuria in renal disease," Annals of Internal Medicine, vol. 148, no. 1, pp. 30-48, 2008.

[72] S. Yusuf, K. K. Teo, J. Pogue et al., "Telmisartan, ramipril, or both in patients at high risk for vascular events," New England Journal of Medicine, vol. 358, no. 15, pp. 1547-1559, 2008.

[73] S. D. Navaneethan, S. U. Nigwekar, A. R. Sehgal, and G. F. M. Strippoli, "Aldosterone antagonists for preventing the progression of chronic kidney disease: a systematic review and meta-analysis," Clinical Journal of the American Society of Nephrology, vol. 4, no. 3, pp. 542-551, 2009.

[74] H. H. Parving, F. Persson, J. B. Lewis, E. J. Lewis, and N. K. Hollenberg, "Aliskiren combined with losartan in type 2 diabetes and nephropathy," New England Journal of Medicine, vol. 358, no. 23, pp. 2433-2446, 2008.

[75] H. H. Parving, B. M. Brenner, J. J. V. McMurray et al., "Aliskiren trial in type 2 diabetes using cardio-renal endpoints (ALTITUDE): rationale and study design," Nephrology Dialysis Transplantation, vol. 24, no. 5, pp. 1663-1671, 2009.

[76] P. A. Kalra, H. Guo, A. T. Kausz et al., "Atherosclerotic renovascular disease in United States patients aged 67 years or older: risk factors, revascularization, and prognosis," Kidney International, vol. 68, no. 1, pp. 293-301, 2005.

[77] C. G. Missouris, T. Buckenham, F. P. Cappuccio, and G. A. MacGregor, "Renal artery stenosis: a common and important problem in patients with peripheral vascular disease," American Journal of Medicine, vol. 96, no. 1, pp. 10-14, 1994.

[78] V. Chabova, A. Schirger, A. W. Stanson, M. A. McKusick, and S. C. Textor, "Outcomes of atherosclerotic renal artery stenosis managed without revascularization," Mayo Clinic Proceedings, vol. 75, no. 5, pp. 437-444, 2000.

[79] J. Webster, F. Marshall, M. Abdalla et al., "Randomised comparison of percutaneous angioplasty vs continued medical therapy for hypertensive patients with atheromatous renal artery stenosis," Journal of Human Hypertension, vol. 12, no. 5, pp. 329-335, 1998.

[80] B. C. Van Jaarsveld, P. Krijnen, H. Pieterman et al., "The effect of balloon angioplasty on hypertension in atherosclerotic renal-artery stenosis," New England Journal of Medicine, vol. 342, no. 14, pp. 1007-1014, 2000. 
[81] L. Bax, A. J. J. Woittiez, H. J. Kouwenberg et al., "Stent placement in patients with atherosclerotic renal artery stenosis and impaired renal function: a randomized trial," Annals of Internal Medicine, vol. 150, no. 12, pp. 840-848, 2009.

[82] K. Wheatley, N. Ives, R. Gray et al., "Revascularization versus medical therapy for renal-artery stenosis," New England Journal of Medicine, vol. 361, no. 20, pp. 1953-1962, 2009.

[83] C. J. Cooper, T. P. Murphy, A. Matsumoto et al., "Stent revascularization for the prevention of cardiovascular and renal events among patients with renal artery stenosis and systolic hypertension: rationale and design of the CORAL trial," American Heart Journal, vol. 152, no. 1, pp. 59-66, 2006.

[84] D. R. J. Kuypers, "Immunotherapy in elderly transplant recipients: a guide to clinically significant drug interactions," Drugs and Aging, vol. 26, no. 9, pp. 715-737, 2009.

[85] R. N. Formica Jr., A. L. Friedman, M. I. Lorber, J. D. Smith, T. Eisen, and M. J. Bia, "A randomized trial comparing losartan with amlodipine as initial therapy for hypertension in the early post-transplant period," Nephrology Dialysis Transplantation, vol. 21, no. 5, pp. 1389-1394, 2006.

[86] I. J.M. Scheffers, A. A. Kroon, J. Schmidli et al., "Novel baroreflex activation therapy in resistant hypertension: results of a European multi-center feasibility study," Journal of the American College of Cardiology, vol. 56, no. 15, pp. 1254-1258, 2010.

[87] M. D. Esler, H. Krum, P. A. Sobotka et al., "Renal sympathetic denervation in patients with treatment-resistant hypertension (The Symplicity HTN-2 Trial): a randomised controlled trial," The Lancet, vol. 376, no. 9756, pp. 1903-1909, 2010. 


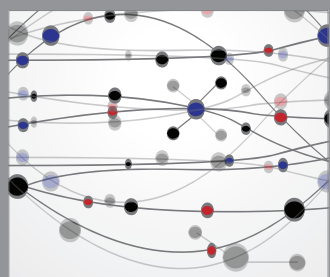

The Scientific World Journal
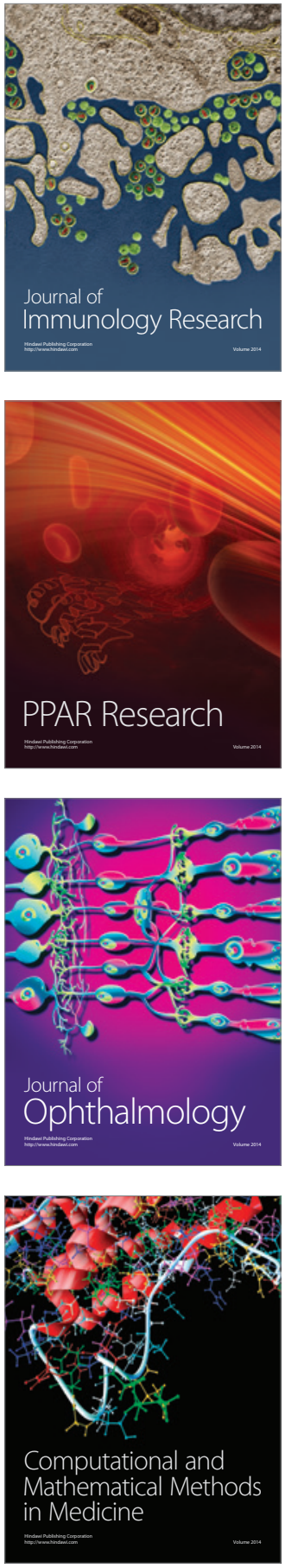

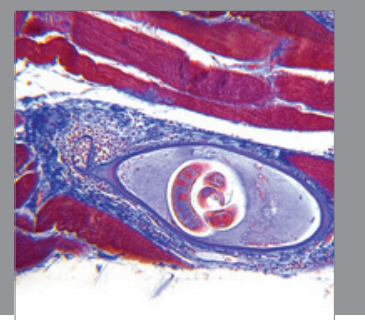

Gastroenterology

Research and Practice
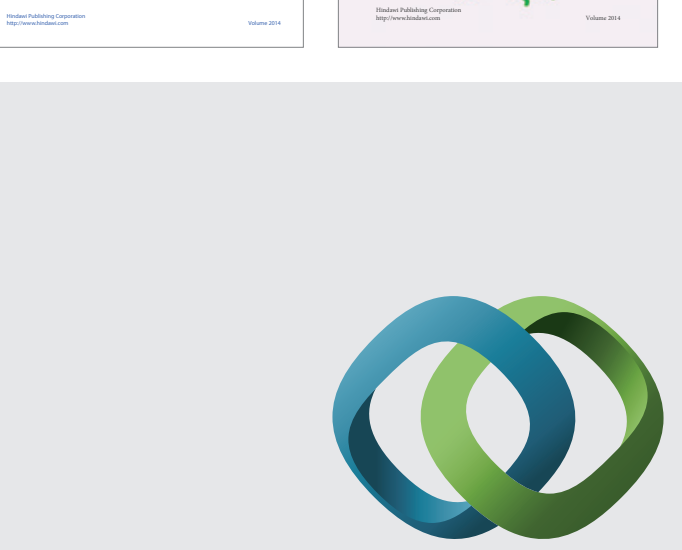

\section{Hindawi}

Submit your manuscripts at

http://www.hindawi.com
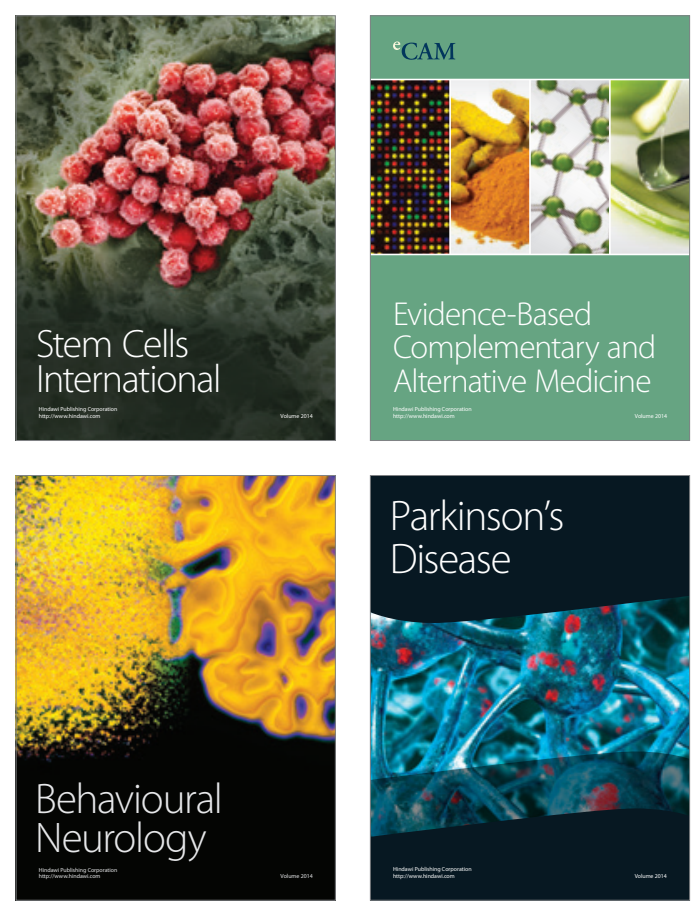

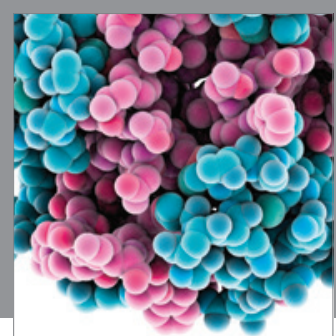

Journal of
Diabetes Research

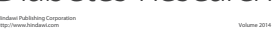

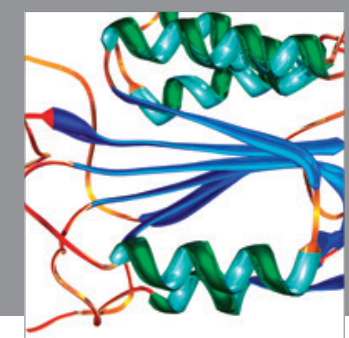

Disease Markers
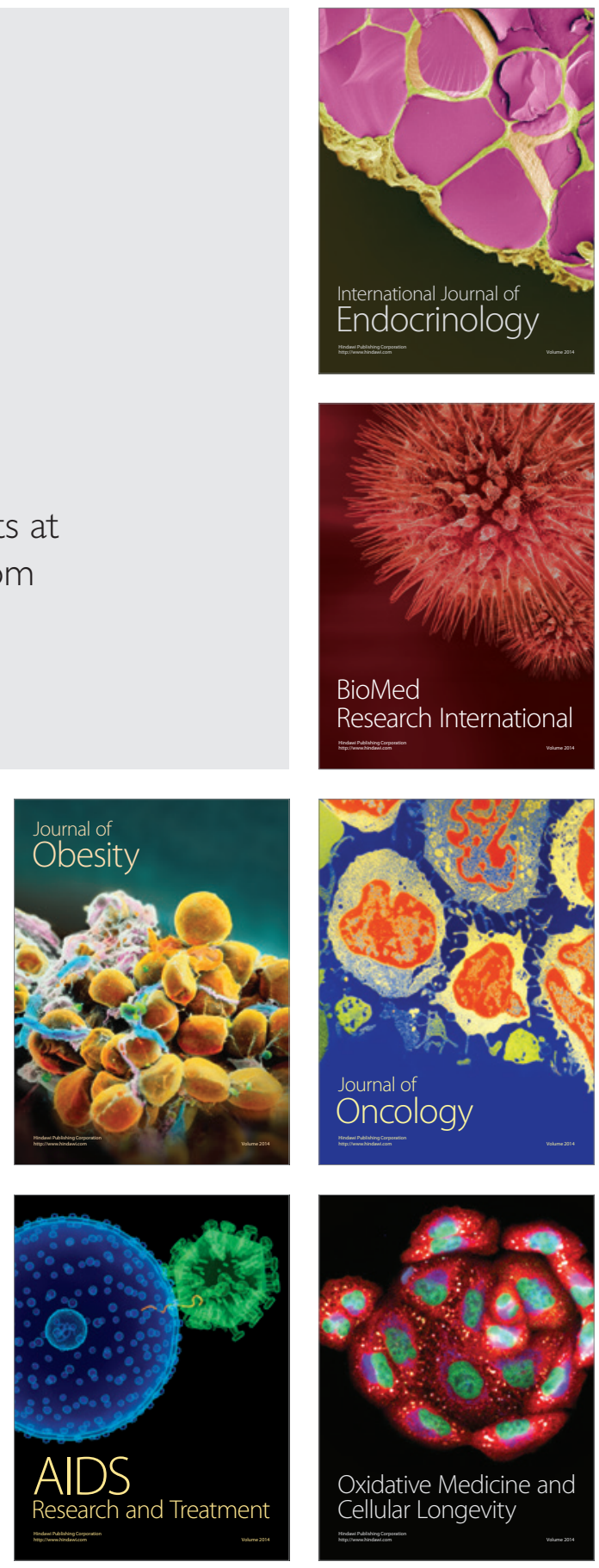